\title{
Design and Fabrication of Smart Waste Collection System
}

\author{
Ashutosh Kumar Singh, Sonal Singh, Garvit Saini, Khushboo, Rajat Mehrotra
}

\begin{abstract}
Waste collection system is the phenomenon or process of carrying solid waste from the area where waste is produced (residential, industrial, commercial, institutional) to the area where this garbage or waste was get decomposed using a suitable process. In the present scenario, the most frequent type of waste collection is by picking the waste from each individual's house or garbage location point or garbage collecting station (community bins or dustbins). These solid waste management systems have been following up since the ninth century. Furthermore, Traditional way or we can say that old municipal waste handling systems in historical centers as well as in metropolitan cities are often made problematic by old infrastructures, Garbage trucks are unable to carry lots of garbage at a single time due to its capacity problem due to this reason the trucks will make two to three or even more rounds for picking up the garbage from the same spot which responsible for increasing the transportation cost. In these circumstances, Fabrication of a vacuum waste collection system arises as a great solution, even in rural locations. This waste management control system lets integrate waste collection from the extruder. It is applicable only at there is a homogeneous type of waste is present.
\end{abstract}

Keywords: Accessibility, fabrication, vacuum systems, extruder, etc.

\section{INTRODUCTION}

$\mathrm{T}_{\mathrm{h}}$ he working and principles required for managing the waste collected from its point of generation to its point of decomposition include several processes like collection, transportation, treatment, and disposal of waste. Waste management is something that every household as well as every citizen in the world requires. Because of increment utilization of most recent advances leads in the pressing of merchandise additionally make the strong waste. The pressing of merchandise gets testing as it produces a straightly

Revised Manuscript Received on June 15, 2020.

* Correspondence Author

Ashutosh Kumar Singh, Electrical \& Electronics department, GL Bajaj Institute of Technology and Management, Gr. Noida, India. E-mail: ashutoshsinghs100@gmail.com

Sonal Singh*, Electrical \& Electronics department, GL Bajaj Institute of Technology and Management, Gr. Noida, India. E-mail: ssyadav7897@gmail.com

Garvit Saini, Electrical \& Electronics department, GL Bajaj Institute of Technology and Management, Gr. Noida, India. E-mail: garvitsaini011@gmail.com

Kushboo, Electrical \& Electronics department, GL Bajaj Institute of Technology and Management, Gr. Noida, India. E-mail: ky82552@gmail.com

Rajat Mehrotra, Electrical \& Electronics department, GL Bajaj Institute of Technology and Management, Gr. Noida, India. E-mail: rajatlmp@gmail.com

(C) The Authors. Published by Blue Eyes Intelligence Engineering and Sciences Publication (BEIESP). This is an open access article under the CC BY-NC-ND license (http://creativecommons.org/licenses/by-nc-nd/4.0/) changing arrangement of parameters for the strong waste administration offices. The expanded sum or employments of plastics and the employments of solidified nourishments which is useful to lessen the amounts of food squanders in the home however increment the amounts of waste at rural handling units. Hence, directly or indirectly every citizen of the country creates waste in the form of agriculture wastes, mineral wastes, industrial wastes, medicinal wastes, and also residential waste in the society[1]. That is the reason the decay of a wide range of these previously mentioned strong waste has become significant issues for the administration of various nations on the planet since it makes ecological issues and natural contamination. Squander isn't in the single structure it very well may be strong, fluid, or gas and each type has various strategies for removal and the executives. Squander the board framework manages a wide range of waste, including modern, organic, and family unit squanders. At times, waste can likewise be risky to human wellbeing. As we realize that waste is delivered by the human movement itself, for instance, the extraction, and handling of crude materials. Squander the board is proposed to decrease the unfriendly impacts of waste on human wellbeing, condition, or feel [2].

\section{A. Types of waste generated:}

a) Food Waste: Food waste or food loss is food that is wasted, lost, or not eaten. Causes of food waste or food loss are numerous and occur at the different stages of producing, processing, retailing, and consuming there is $27.9 \%$ of food-based among the solid waste produced in India. Loss and wastage of food happen at all phases of the food chains. In low-pay or developing nations, a large portion of the food wastage happens during the creation stage, while in created nations food squandered at the utilization stage.

b) Glass waste: Approximately about $45 \%$ of glass waste gets through the process of recycling in India every year. Because glasses are made up of plastics and unfortunately it can't be decomposed due to its chemical properties that are why it is very much important to recycle it.Glass is almost $100 \%$ recyclable and can be recycled endlessly without loss in its quality or purity. According to the survey, there is only $6 \%$ of the total waste is glass waste.

c) Plastic Packaging: According to FICCI, which is an Industry body India is in the third position in plastic packaging around the world. As per a report by the ministry of housing and urban affairs, $70 \%$ of plastic packaging is turned into waste in a short span. It contains $7.6 \%$ of the total solid waste produced in India.

d) Pet Waste: According to the survey, Pet waste contains $7 \%$ of total waste. India is turning waste into an opportunity by recycling $90 \%$ of its $\mathrm{PET}$ waste, higher than Japan, Europe who recycled around

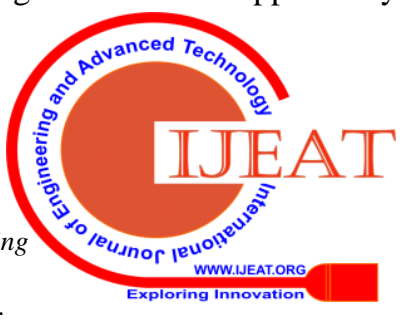




\section{Design and Fabrication of Smart Waste Collection System}

$72 \%$ and $48 \%$ of its discarded PET. The PET bottle recycling in India is a Whooping INR 3500 crores industry now.

According to report declared by the Council of Scientific and Industrial Research (CSIR) and National Chemical Laboratory (NCL) after a year-long study it was discovered that out of the $900 \mathrm{kilo}$ tons of plastic produced in Indian annually, around $65 \%$ gets recycled at registered facilities, $15 \%$ recycled in organized sectors left $10 \%$ reused in households and the rest ends up in landfills [3].

e) Paper Waste: Paper waste is the second-largest waste produced in our country i.e. $14.9 \%$ of total waste. In India, approximately more than 550 mills make use of paper waste as the main and efficient raw material for making paper, paperboard, and for the production of newsprints. In India, every year around 3 million tons of waste paper is recovered, which is only $20 \%$ of the total paper waste. When we compare this figure with other countries, the amount is comparatively very low. For instance, developed countries like Germany recovers $23 \%$ waste paper, Sweden $69 \%$ paper waste, Japan $60 \%$ paper waste, USA $49 \%$ paper waste, etc.

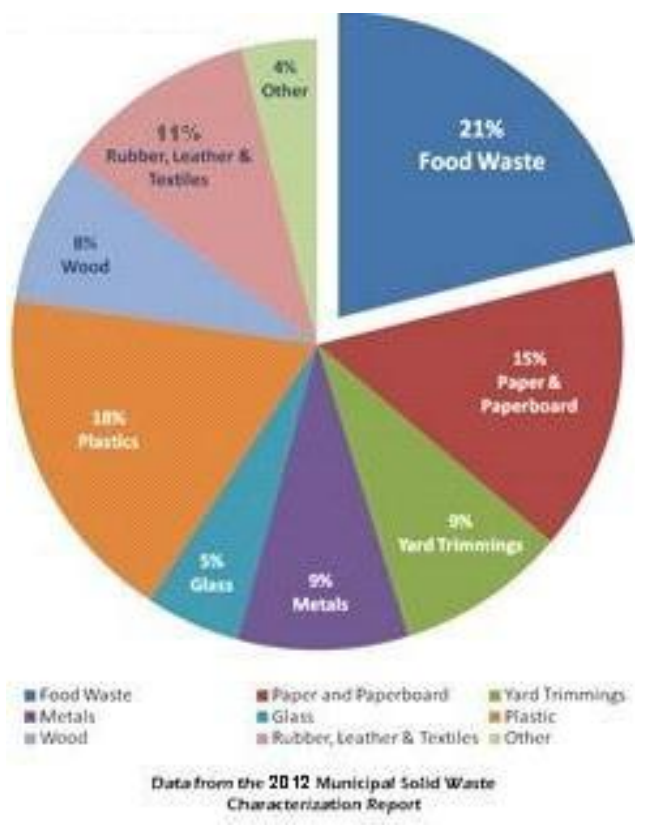

Fig 1. Pie chart shows the type of waste present in our surroundings.

f) Other Wastes: Other wastes such as tire scraps of the metals, etc. are used as raw materials by the industries which are involving in the recycling of such types of garbage, or we can say that waste. Accordingly, it is always preferred to utilize such waste through the 3R technique which is Reduce, Reuse, and Recycle. It serves the purpose of clearing the areas where homogeneous waste is present. It also ensures clearing in small areas as well as large areas. It helps in the reduction of hazardous diseases caused by pollution and garbage. It also increases the garbage capacity by decreasing the expense while transportation of the garbage by compressing the garbage through vacuum pressure.

\section{B. Municipal Management of Waste}

In urban areas, the Municipalities and Municipal Corporations systems were developed by the government, which works as the local governments or self-governments for managing the urban services. The Municipal organization itself settles on the choice and becomes a self-mindful government for giving fundamental necessities, needs, or as per the arrangements made in different enactments administering the neighborhood bodies in the states or neighborhoods. In India, the Municipalities or metropolitan framework doesn't get a lot of money related or efficient help from the State or Central Government. That is the reason they should create their budgetary assets. The littler Municipalities have scarcely any assets or don't have any sort of store to meet their everyday prerequisites because of which they don't can take activities for overhauling the degrees of administrations. Raising costs, shortage of assets, indiscipline among workforces, and so forth are making the circumstance awful with time or step by step. In metropolitan cities or the cities where the population was quite high, the situation is rather complicated and difficult. These problems are responsible for the failure of the Municipal Waste Management System.

\section{Existing methodology of street cleaning}

As we see, the cleaning or sweeping of streets is settled two times in a single day i.e. in the morning session and afternoon session. The sweepers perform 6 to 8 hours of total work. The 4hours work is done in the morning from 6 to 10 A.M. and in the afternoon from 2 to 6 P.M. The schedule is different from one city to another city. There are also some cities in India where a continuous duty of 6 to 8hours takes place regularly. The sweeping of roads is done in the morning sessions. There are some separate areas are allotted for the afternoon sweeping. After making attendance sweepers have to travel a long distance to reach their workplace. Sometimes they may have to walk for more than $3 \mathrm{~km}$ distance to outstretch their workplace.

Sweepers use long-handled or short-handled brooms to sweep streets. Initially, they make small heaps of waste on streets while sweeping through brooms, and then they scavenging the waste heaps into the hand carts or bullock carts. They pick-up the waste with the help of metal plates or any kind of waste in the baskets and then in the bullock cart or hand cart. While in some areas in place of using hand cart or bullock cart another sweeper follows the sweeper on foot and pick-up the heaps of waste made by the first sweeper in the basket and walks for 50 to $100 \mathrm{~m}$ by collecting this waste into the basket and then put this collected waste into the storage-bins i.e. dust-bins provided by the municipal community [8].

a) Tools used for street cleaning: Generally, street cleaning is done by the bamboo brooms which are either of long-handle or short-handle. The brooms used in different cities are of different kinds there is no uniformity in the shape, size, and quality and quantity of brooms provide to sweepers. The quantity of brooms provided to the sweepers is different. In some cities, they provide 3 brooms per month, and at some other places, they provide only 1 broom per month, with $1.5 \mathrm{~kg}$ of bamboo-sticks every six months. The life of Bamboo sticks is not more than 8-9 months, this hardly lasts for one year. The life of bamboo brooms depends on the length of the streets or roads that need to be swept, or on the quality of bamboo-sticks, on the types of roads and streets. The efficiency of sweepers reduced due to the inadequate supply of tools.

Published By:

Blue Eyes Intelligence Engineering

\& Sciences Publication

(C) Copyriaht: All riahts reserved.

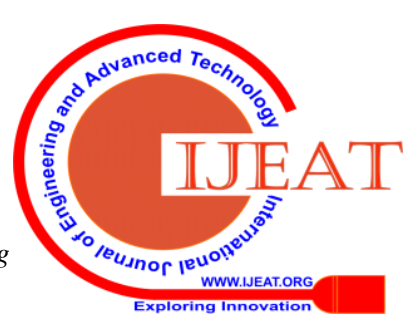


b) Waste's Debris problem: In the construction and demolition the debris lying on the roadsides is the major problem in the cities. This waste is hefty and commodious and also arduous to handle. The building contractors are presumed to follow a different route for the transportation of the construction and demolition debris. Generally, the demolition and construction debris are often dumped along-with the streets and municipal waste into the bins. While cleaning it creates an extra problem for the municipal crew, due to the huge weight of the waste and large quantity of the waste (Omkar and Srikant, 1996).[4]

c) Transportation of waste: There are two stages of transportation of waste i.e. first, transfer of waste from waste bins or dustbins to conveying vehicle, other is fetching of waste to dump sites. The first stage is generally carried manually by the laborers provided on every vehicle. The waste is transferred from the dust-bins to the vehicles by the laborers using baskets and hand carts. The transport vehicle moves bin-to-bin along with laborers until the vehicle is full. This whole process is carried out manually in this existing system. There is a possibility of infection in all these stages either by direct contact or gasping (inbreathing) of dust, fumes, etc. of transferring the waste. Hence, it is attainable to lessen the taking care of steps of waste assortment to a base. The courses are subjectively fixed along which the vehicles move. 60-70 percent of the absolute consumption is supported on decline transportation. The most extreme of the vehicles are currently outfitted with tipping gear and thus laborers need not head out to dump destinations alongside the full vehicle. (Bhide, 1994).[5]

d) Total Waste Generation: The estimation of hard and fast waste age by 217 million people living in urban domains is 23.86 million tons for every year (1991 position) and it may cross 39 million tons by 2001 A.D. Today Indian urban regions make assessed 80,000 tons of city solid waste (MSW) normal [6] in the latest decade, MSW conveyed at about twofold the pace of people advancement. About a fourth of India's masses live in urban agglomeration. The present urban people is 220 million and is depended upon to create to 470 million continually 2010. In the coming days, the Indian urban regions will be among the most thickly populated urban regions of the world. With a lot of India's masses booked to live in urban zones, the MSW makes moves to gateway wild. As showed by the 'World Resource Report (1996-97)'[7], Mumbai, Delhi, Madras, Bangalore, Lucknow, Varanasi, Hubli, Mysore, Gulbarga, Bhiwandi and Tumkur delivered $0.50,0.44,0.29,0.16,0.31,0.14,0.15,0.26,0.13,0.10$, and 0.13 metric tons/per capita/yearly exclusively as shown in figure 2. Statistics of waste disposed off in Hong Kong city is given in figure 3 .

e) Fabrication: Since we all are well known about big rowdy waste collection trucks that patronize our businesses and vicinity. Does the AVAC (automated vacuum waste collection system) soon make these familiar trucks a thing of the past? As we are becoming aware of finer air quality and preferable climate pliability, it's a definite possibility. As these AVAC systems are already augmenting fast in marketability, with units appearing in major cities of the world like Barcelona, London, Stockholm. This concept of these systems may look intricating, but these systems have been in place for many years and the technology is prodigiously complex. Waste collection points are placed on the surface in both indoor and outdoor areas after underground pipes have been installed accessible 24hrs a day. The sensors inside them signal the waste levels triggers the beginning of the emptying process, until then the waste remains under the surface at these collection points. As we know that the garbage trucks do not carry the garbage in tons in a single time but it will have to come many time to collect the garbage and the transport it to the decomposition station and but as soon as we can add this approach to the garbage trucks lots of garbage can be easily transported.

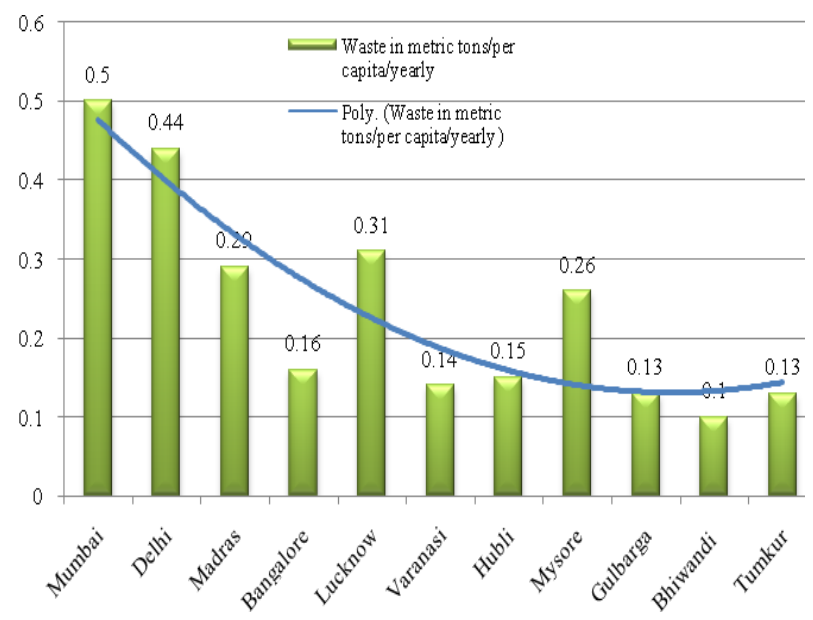

Fig 2. Waste in metric tons/per capita/yearly

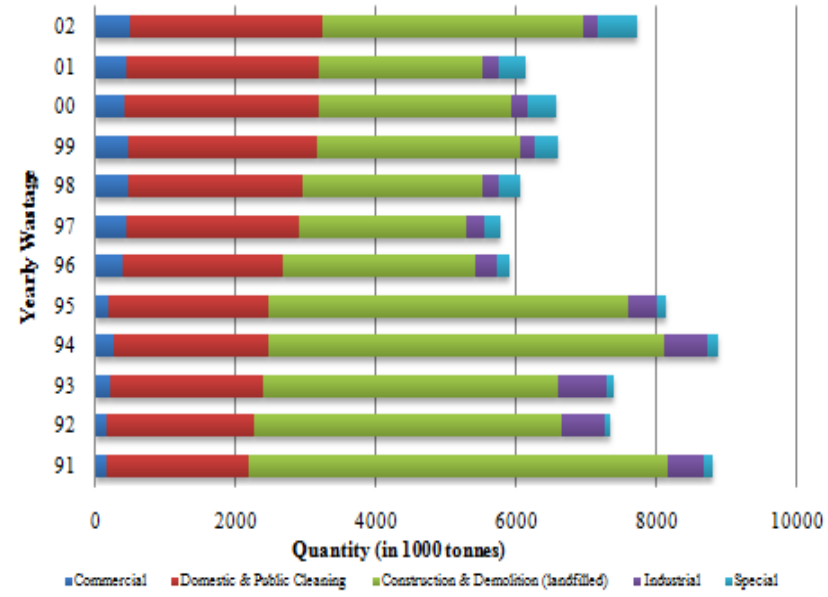

Fig 3. Magnitude of Solid Waste Disposed off in last decade

D. AVAC (Automated Vacuum Collection Systems): A new collection method introduced in recent years is the vacuum collection system that automatically transports refuse to a central terminal or treatment facility. In this approach, we use to fabricate the waste or garbage collected by us. We use the application of vacuum and extrusion to fabricate the waste product. As we know that the garbage trucks do not carry the garbage in tons in a single time but it will have to come many times to collect the garbage and transport it to the decomposition station but as soon as we can add this approach to the garbage trucks lots of garbage can be easily transported.

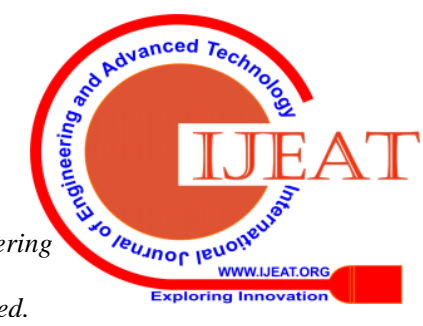


Squander practices are not consistent among nations (developed and advancing countries); locales (urban and rustic regions), and private and mechanical segments would all be able to take various recommendations. As we are becoming conscious of better air quality and climate pliability, it's a definite possibility. Waste collection is a part of waste management, it is the transfer of solid waste from the point of use and disposal to the point of treatment or landfill [8].

\section{Properties}

- The absolute pressure head is $0.75 \mathrm{~m}$.

- The power rating of the motor is 1400 watt.

- It generates more suction power as compared to its earlier usage.

- It can suck dry garbage easily.

- It is portable.

- Extruder helps in reducing the size of garbage

a) The requirement of the AVAC system: The collection of waste also includes the kerbside collection of recyclable materials that technically are not waste, as part of a municipal landfill diversion program. As many we are becoming more conscious of good air quality and also towards the health of our environment. As the awareness grows for both air quality and environment then AVAC systems may help for the improvement of both of those. If we use AVAC systems this will limit the use of Garbage trucks and the limitation of using the garbage trucks is the main advantage for the environment. By using the AVAC systems, the trucks will collect the garbage only from the bins or collecting areas at the outsides of the societies instead of circling the trucks from home-to-home or door-to-door. In this perspective, AVAC systems will be beneficial for cost-saving and also limits air pollution. These AVAC systems do not require a lot of laborers for functioning and maintenance, hence the companies which are operating them would not have too many employees. As the number of Garbage trucks need to pick-up and dispose of the waste in these systems is significantly less than the normal Garbage trucks. These systems encourage users for more efficient recycling. AVAC systems are new collection methods introduced in recent years, they are vacuum collection system that automatically transports refuse to a central terminal or treatment facility. In this approach, we use to fabricate the waste or garbage collected by us. We use the application of vacuum and extrusion to fabricate the waste product. As we know that the garbage trucks do not carry the garbage in tons in a single time but it will have to come many times to collect the garbage and transport it to the decomposition station but as soon as we can add this approach to the garbage trucks lots of garbage can be easily transported.

b) The novelty of project: It serves the purpose of clearing the areas where homogeneous waste is present. It also ensures clearing in small areas as well as large areas. It helps in the reduction of hazardous diseases caused by pollution and garbage. It also increases the garbage capacity by decreasing the expense while transportation of the garbage by compressing the garbage through the vacuum pressure.

\section{E. Community-Based And Non-Government Organisations(Ngos)}

a) Waste Reduction: Nowadays in the urban areas of developing countries, a major part of wastes generated is not being recycled. And most of the waste dump sites are located in rural areas to continue the growth of metropolitan cities, so this causing extra transportation expenses of waste. So, the problem is we don't know how to reduce transportation expenses? One way to reduce is slowing down the amount of local waste to be transported by the government at dumpsites so this called "waste reduction". So, how we reduce waste. Domestic waste contains more of the wet stuff. Recovering an inorganic substance or separation from a wet substance. At this time most of the domestic waste is caused by inorganic material so that means cities are encouraging the separation of wet and dry waste for re-use of waste. The waste separation to diverting consumption residue from fixed disposal at grassroots increasing the recycling of waste substances can give to the higher level of waste separation.

\section{F. Advantages Of The System Over Existing Systems-}

Most people are becoming tensed because of air quality and environmental health. Reducing the number of dustbin boxes in trucks. first environmental benefits of this system. They only truck the garbage from waste stations to dump sites by breaking the usual rule of circling residential areas stopping at each door. And these systems don't need lots of human power. So lots of companies don't need to pay many humans. And some of the other benefits are the waste is not piling up and causing foul odor and, It also increases users to recycle more significantly. It prevents scavenging.

\section{LITERATURE REVIEW}

Yashwant M. Sonkhaska et al. [11], tells about the manufacturing of bottles. another side would help in waste reduction. its uses are increasing day by day. Many actions were taken by the waste management to circumvent this issue in the past but no major results were achieved. Authors in [12] has been elaborated about the experimentation of can or plastic bottle device machine and the analysis used in the machine so by the study of this data and analysis of the assorted elements the standard and the life of the machine is improved and increased in the experimentation this machine includes processes like style fabrication analysis and collection of many parts etc. By this data, all the parameters like style fabrication and analysis can get increase and the utilization of work table code will increase each day. TrushaliS.Vasagade, et al. [13] Solid waste management is one of the major sides which has to be in mind in terms of making city areas environmental healthier. The waste hierarchy refers to the "3 Rs" Reduce, Reuse, and Recycle, which classifies waste management strategies according to their desirability in terms of waste minimization. The waste hierarchy is the cornerstone of most waste minimization strategies. The waste hierarchy aims to extract the maximum practical benefits from products and to generate the minimum amount of end waste; see resource recovery. The waste hierarchy is represented as a pyramid because the basic premise is that policies should promote measures to prevent the generation of waste.

lished By:

Blue Eyes Intelligence Engineering

\& Sciences Publication

(C) Copyriaht: All riahts reserved. 
The next step or preferred action is to seek alternative uses for the waste that has been generated i.e. by re-use. The next is recycling which includes composting. Home domains un-isolated waste is assembled at the control side or from waste move stations and subsequently masterminded into recyclables and unusable waste. Such systems are fit for masterminding tremendous volumes of solid waste, safeguarding recyclables, and changing the rest into biogas and soil conditioner. In San Francisco, the close by the government set up its Mandatory Recycling and Composting Ordinance in favor of its goal of "Zero waste by 2020", requiring everyone in the city to keep recyclables and compostable out of the landfill. The three streams are assembled with the curbside "Mind-boggling 3" repository structure - blue for recyclables, green for compostable, and dim for landfill-bound materials - provided for occupants and associations and upgraded by San Francisco's sole decrease hauler, Recology [14].

V.B. Dzobelova, et al. [15] tell that In most created nations, residential waste removal is subsidized from a national or nearby duty which might be identified with salary, or property estimations. Business and mechanical waste removal are regularly charged for as a business administration, frequently as a coordinated charge which incorporates removal costs. This training may urge the removal of temporary workers to select the least expensive removal choice, for example, landfill as opposed to the ecologically best arrangement, re-use, and recycling. In a few regions, for example, In Taipei, the local government charges its families and organizations for the volume of trash they produce. Waste is assembled by the city board of trustees just in case it is put in government-if garbage packs. Authors in [16] state in their paper waste generated is a global level problem. There is a proper way to disposing of solid waste contaminate all the elements of the inexperience setting (air, land, water) at local and international levels. It is because the economic process in urban areas is on its speed. The main cause of the continual flow of garbage is individual unsanitary activities. And for boosting cleansing and avoiding such a scenario we have to go with the 'smart waste management system ' plan. In this planning system, the dustbins are regularly checked for its completeness of waste by the assistance of the system and the info is shipped to the particular room. Jia-Wei Lu, et al. City area solid waste and employment area unit required at the basics scale instead of hopping on the treatment and disposal at the regional scale. To fill this gap they construct an economical, effective, and proper theme, this study created a vital and inexperienced system (SGS) that embodies the in-depth integration of assorted information processing and also the strategy of property waste management. The planned SGS is ready to gather a large amount of information and knowledge from the completely different application of waste separation and differentiated assortment to regular check-in states parameters they took the help of device network technologies and the rate of waste separation and employment. In-network processing and cloud computing contribute to managing the communications among all assortment nodes, vehicles, and crews in a very secure, ascendible, and highly-available setting. The planned SGS will Integrate three-level SGS design with an ascendable device network is projected during this study as an instruction of developing SGS for property waste management. Good and inexperienced Urban Solid Waste

assortment Systems: Advances, Challenges, and Perspectives [17] This paper gives a detailed literature review of ongoing progressive analytical thinking techniques for city solid waste assortment and identifies four intrinsic deficiencies of the current studies over different kinds of cities. As an explanation, a multi-constrained and multi-compartment routing downside is shape constricted a two-stage decision-making method to exhibit the very best tough-ness of its kind in sensible implementation. The constraints of your time windows, intermediate facilities, multi-shifts, and split deliveries create a perfect combination of all essential complexities in modeling practices. to solve the problem, a unique kind of algorithm is proposed for addressing node routing and clearing routing problems. The proposed rule that contains data format and improvement shifts solves the models with numerical potency to look for the foremost cost-efficient and environmentally benign solutions. Results show that separated assortment will give more chances to pursue the most effective routing strategy with property implications by sensitivity search at the expense of upper assortment cost. The search concludes with the views of a sensible and inexperienced waste collection system designed to make additional property waste management systems within the future. Design and Fabrication exercise of Plastic System [18] The extruder of the plastic machine is involving the 5 rule parts; they're compartment, a drive of the screw, barrel, and spout (pass on), radiators, and structure. The extruder is that the prime a bit of the machine wherever inside the crushed particles gets brought into wires through a pass on. The screw is that the center of the extruder, that uses segments through its length. The glow for melting the Crushed plastics is the board-driven using a warming control unit. The Screw, that is motor-driven gives the melted Plastic to the opening of the kick the can.

L. Liu et al. [19] discusses a couple of violation approach for the observance of regional/urban solid waste management systems beneath uncertainty, supported a special technique referred to as -interval-parameter fuzzy whole number programming\| (IPFIP) model. during this approach, given levels of violation system constraints allowable square measure additional tolerable. the choice house of the model is explained exploitation the crucial constants referred to as the violation variables. Violation analyzing the theme doesn't satisfy all the model original constraints. This technique offers cheap solutions through this design. at intervals, the management system tiny low info relating to the growth of facility and waste flow calls were created generated. The results of modeling generate a series of choices beneath system acquisition, permits for additional in-depth analysis of tradeoffs between the atmosphere and economic things additionally as those between system responsibleness and optimality. This whole model depends on the various selections taken by the user with every step within the project. This plays a serious role in the system's progress. G.J. Manderson [20] discusses the number of solid-waste made from industries in developing countries which will not be unnoticed.

Blue Eyes Intelligence Engineering \& Sciences Publication (C) Convriaht: All riahts reserved. 
The safe disposal that's desperately needed because the amount is increasing day by day. Reducing the amount of solid waste made within the cities and cities is that the beginning of life. but volume reduction is simply one life to the matter. we want to convert solid waste to non-harmful waste that's not harmful to the atmosphere. completely different strategies of moldering each agricultural and industrial waste are mentioned. one in all them is that the cleaner technology wherever the assembly of waste in industries is often decreased. Cleaner technology includes 5 steps particularly designing and organization, pre-assessment, assessment, feasibility study, and implementation. Recycling of waste is the key activity of cleaner technology. The waste assortment is needed to be done on a commonplace because the dirt cannot be left while not treatment in an open house.

Pankaj M. Patil, Prof. D.B. Sadaphale [21] discuss that Extrusion is far and away from the foremost necessary and doubtless the oldest transformation and shaping method of thermoplastic polymers. to confirm a top quality through the extrusion method throughout producing, it's essential to find, control, and monitor all quality parameters. a number of the necessary parameters square measure state of equipment, operating conditions, temperatures, pressures, quality of dies, materials, and cooling medium. rather than the truthful efforts from the makers, still there square measure variety of obstacles within the method that show the thanks to defects within the product. this paper aims to properly understand the extrusion method and target the assorted defects and their impact on product quality. Ware. E, [22] has explained very well how the extrusion of molten plastic on the wire and also other metal forms needs control of various parameters to make sure that the product quality is maximum at high production rates. There are various advantages of using a controller that helps us accomplish higher levels of coordination and performance and also makes it easy to connect more controls into our system. Seema Nara, et al. [23] said types of equipment like an oven that are categorized as temperature control system does not heat instantly, whereas this time can be reduced with generic algorithm making the temperature control system start instantly. It is not easy to achieve this minimal time limit and at present, the only method available is doing it manually by hit and trial. S.Ravi, P.A.Balakrishnan [24], ], through simulation developed and tested a GA-based Fuzzy logic controller for temperature control in plastic extrusion. The two techniques were designed to change the temperature at different point changes. This process was strong in opposition to changes in the system parameters and superior to the Fuzzy controller.

There is an alternate method that A.K. Kochar [25] proposed for determining plastics extrusion process models is suitable for high-level control are examined. The processes that are carried out for processing polyethylene on a single screw extruder is described with the outcome results. C.C.Tasi and C.H.Lu, [26] described the design of single loop fuzzy supervisory predictive PID controllers for a plastic extruder barrel. To improve the set-point tracking performance a fuzzy supervisory shell is proposed. M. P. Groover [27], Fundamentals of Modern Manufacturing discuss that extrusion is a high volume manufacturing procedure. The plastic material is brought into wanted shape by the warmth and extruder through kick the bucket. The liquid plastic material is constrained through a bite of the dust by a round and hollow pivoting screw which is put in the barrel. The expelled substance changes the shape as per the cross-segment of bite the dust. In Instruction Manual. CBW Granulators[28] it is talked about that the huge particles of plastic must be separated into little pieces so that to lessen capacity and transportation space prerequisites. Such separated HDPE, PP, LDPE plastics are sold as crude material for plastic creation moving along without any more handling. The smasher ought to incorporate a turning set of sharp edges, an engine, and taking care of the container. the greatest size of the plastic that should be squashed decides the size of the feeder.

\section{METHODOLOGY}

The vacuum pump is mounted on the one end of the drum, when turning on vacuum pump then it creates a pressure difference into the drum due to which it sucks the lightweight garbage is to be sucked like paper, polythene, etc. There is a flexible pipe attached to the drum at the top through which garbage is to be sucked. After that whole apparatus is to be mounted on the vehicle which is manually driven and the suction pipe is mounted at the base of the vehicle in T-shape so that it sucks the garbage which comes under it. Hence, The collected garbage is taken off from the drum and passed into the chamber in which there are a screw and nut mechanism of the injection extrusion process to compress the garbage. The main objective of this approach is to decrease the volume of the garbage by crushing it which is responsible for increasing the capacity of garbage vehicles`. This approach also reduces transportation costs.

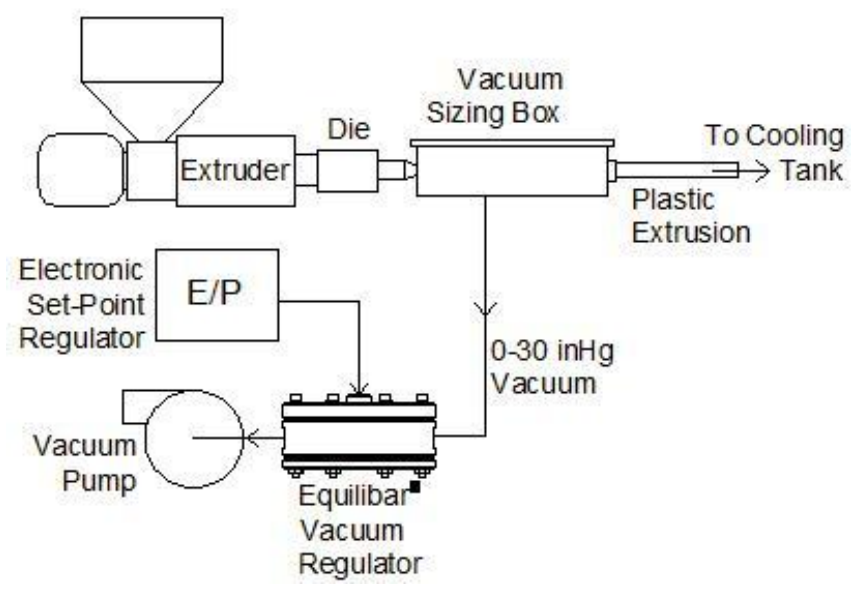

Fig 4. System Setup

\section{A. Extruder machine}

The method used in the building of the planned instrument consists of operation on lathe machine, electric welding using an arc welding machine, keyway cutting on slotting machine, operation on drilling machine, boring process on lathe machine, grinding for good finishing, flame-cutting using an oxyacetylene gas welding machine.

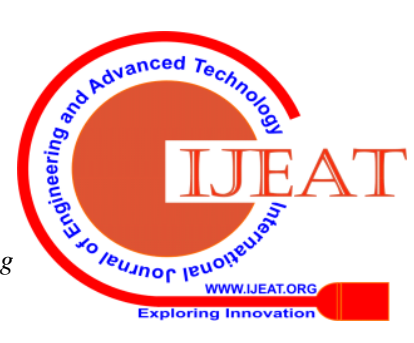




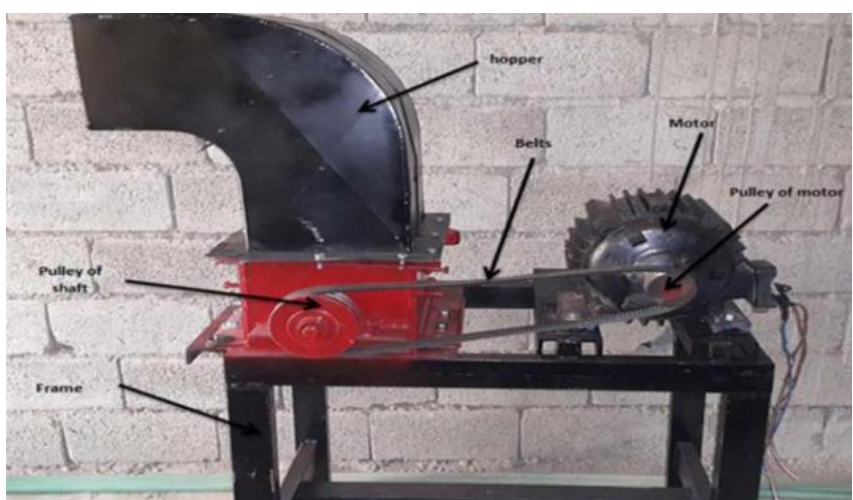

Fig 5. Extruder image

\section{a) Hopper of the Extruder machine}

The sheet plate that has a thickness of $1 \mathrm{~mm}$ is taken and this sheet should be cut by the general sheet metal shaping machine and scissors i.e. hand device and afterward the sheets are joined by opposition spot welding The container is accustomed to taking care of plastic into the barrel.

\section{b) Barrel and Nozzle of the extruder}

The barrel is required for taking care of the softened powder from the container into the kick the bucket by the screw. The measurement of the gap of the spout relies upon the material we have to process and there is no particular procedure as opposed to experimentation for finding the precise components of the equivalent. The process takes the outside of the tooth copper mouth spout outlet gas/pipe to connect the tube. The spout is made of copper material and is utilized to take care of the liquefied plastic from the barrel for item molding.

\section{c) Shredder/Crasher Machine}

These raising procedures were separate into four subheadings to be specific: welding activity, cutting activity, machining activity, welding activity, and get together, and completing the activity.

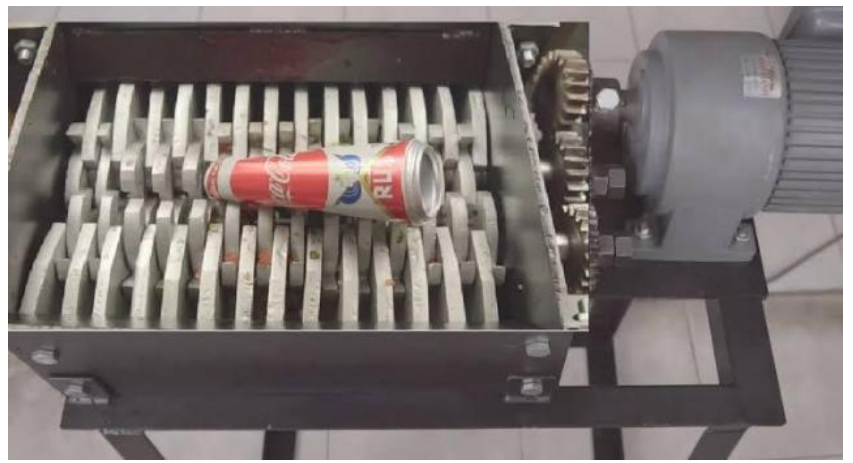

Fig 5. Plastic shredder/crusher machine

d) Hopper Construction: The sheet plate whose thickness is $2 \mathrm{~mm}$ is taken for making a shape like a pipe of the wind current that is the segment region of $30 \mathrm{X} 35 \mathrm{~cm}$ and making 3 gaps from the pipe every four sides by the container is accustomed to taking care of the issue

- Tin galvanize is the material

- $\quad$ The hopper is used to feeding the matter
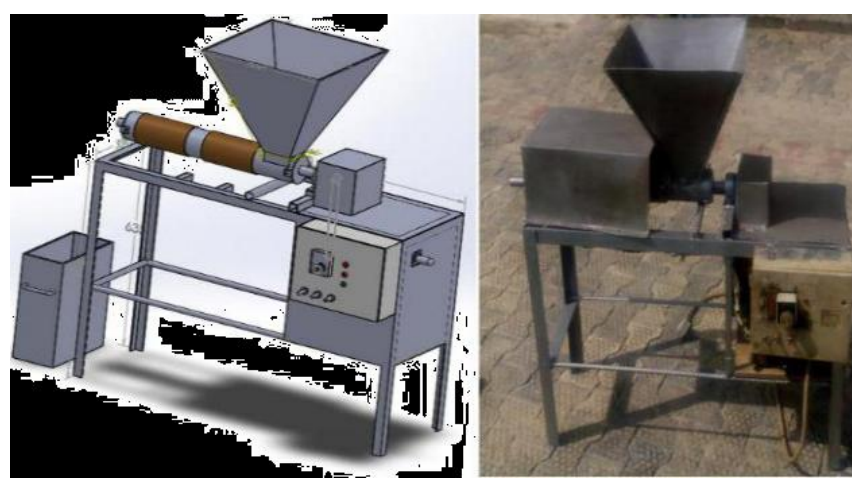

Fig 6. Hopper of the Extruder machine

\section{e) Shaft, support, and knives}

The pole is made of steel and is utilized for pivoting the blades and set the backings which are then utilized to fix the pulley.

\section{f) Construction of the screen}

Carbon steel is the material on the screen.270 are the numbers of the holes. Make the three holes $(15 \mathrm{~mm})$ in the two edges of the screen by penetrating the machine.

\section{g) Process of Extrusion}

Rotation of the screw is the principle of the extruder by using a motor and by using heater the material melts and this extruder is needed a motor and heater when the capacity of the motor is equal to $200 \mathrm{~W}$ the screw rotated by $20-180 \mathrm{rpm}$. The melting temperature of heaters between $(0-400) 7^{\circ} \mathrm{C}$.

\section{B. Vacuum cleaner}

The vacuum cleaner is made that is used to suck the waste when the waste is collected in the bin at desired pressure than the waste proceeds into the extruder which takes the help of hopper since the vacuum cleaner is mounted on the top of the extruder as discussed in the methodology.

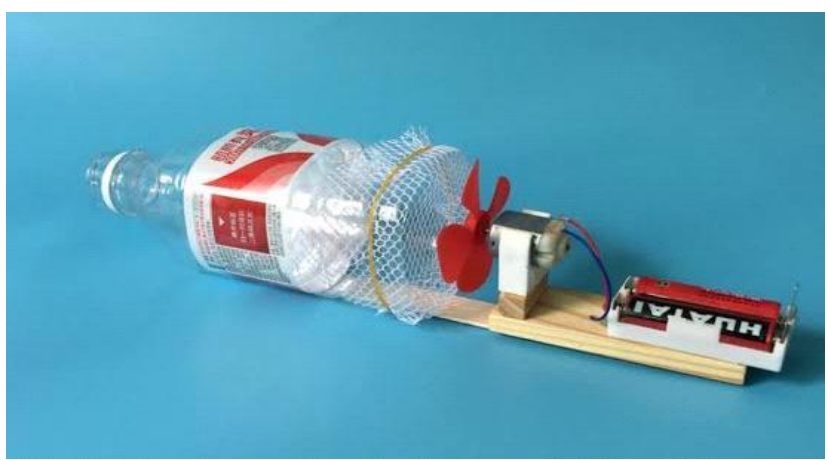

Fig 7. Vacuum Cleaner

\section{RESULT}

We make a vacuum by compressed air but the result was not satisfactory because vacuum pressure is not so good enough. Again we make vacuum by a plastic container of 2 to $2.2 \mathrm{~mm}$ thickness but the result was not satisfied as per our requirement.

Then we used a Hard plastic container of $3 \mathrm{~mm}$ thickness then they satisfy our result.

Published By: Blue Eyes Intelligence Engineering \& Sciences Publication

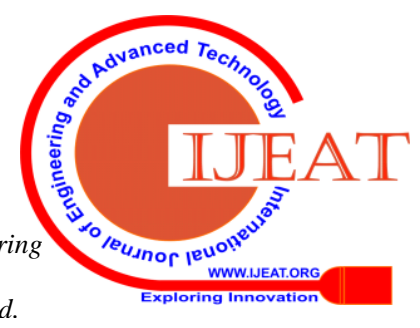




\section{Design and Fabrication of Smart Waste Collection System}

We also crush our dry waste on the extruder, this results in all the waste is extruded except plastic. It can be utilized on the campus of a different organization where homogeneous waste is produced. It can also be utilized in open grounds or packs where there are dry waste materials like paper, polythene, vegetable peels, etc. It can be used on railways stations where instead of picking garbage like empty bottles, newspapers, wrappers, etc. by hand, this machine can be utilized.

\section{CONCLUSION \& FUTURE APPROACHES}

The position of the vacuum pump is very necessary for creating suction pressure. The leakage should be zero so sealing should be proper. The diameter of the pipe should be varying so that suction should be maximum. The suction of the pipe is the function of the length of the pipe. The hole of the suction pipe should be nearest to the vacuum pump length of the pipe should be maximum. For now, we have been using electric supply for the machine to function. In the future, we can also use a battery, solar power, which would be the most efficient way to operate this system. Now we suck dry waste only but in the future, we will suck wet waste also and separate dry waste after suction. For now, we have been working on dry waste, the suction of the dry waste but in the future, we will jump to all kinds of waste as a variety of wastes are available in society.

\section{REFERENCES}

1. Rutqvist, D., Kleyko, D., \& Blomstedt, F. (2019). An Automated Machine Learning Approach for Smart Waste Management Systems. IEEE Transactions on Industrial Informatics.

2. Elhassan, R., Ahmed, M. A., \& AbdAlhalem, R. (2019, January). Smart Waste Management System for Crowded area: Makkah and Holy Sites as a Model. In 2019 4th MEC International Conference on Big Data and Smart City (ICBDSC) (pp. 1-5). IEEE.

3. Zhang, A., Venkatesh, V. G., Liu, Y., Wan, M., Qu, T., \& Huisingh, D. (2019). Barriers to smart waste management for a circular economy in China. Journal of Cleaner Production, 240, 118198.

4. Sureshkumar, M. P., \& Pavithran, S. (2019). Smart Solid Waste Management System Using IOT. International Research Journal of Multidisciplinary Technovation, 1(6), 148-151.

5. Omkar, A.C. and Srikant, R., (1996), Hyderabad City of Garbage‘. In Gopi, K.N. and Ravindra Prasad D. (eds.) Urban Waste Management (Department of Geography and Research Centre for Urban and Environment Studies, Osmania University, Hyderabad, India.

6. Bhide, A.D., (1994), Solid Waste Management in Urban Areas", Nagarlok, Vol. 26, India.

7. World Resource Institute, World Resources,(1996=97)Washington, DC, USA, P. 154.

8. Karanja, A.M., (1996), Alternative Approaches to Solid waste Management Systems` (Daystar University, Nairobi, Kenya).

9. Glave ,James ,Russel ,Terrance (july2010), ॥ Canada Sucks :Montreal's vacuum system will making taking out the trash a breeze.

10. Yashwant M. Sonkhaska, Metin E, Erozturk A, Neyim C (2003) Solid Waste Management. Experimental Research on Crushing Force and its. Distribution Feature in Jaw Crusher 2007 Second IEEE Conference on Industrial Electronics and Applications.

11. S.B.Satish, J.Sai sandeep, B.Sreehari, Yeshwant M. Sonkhaskar, "Designing of a Portable Bottle Crushing Machine" IJSRD International Journal for Scientific Research \& Development Vol. 4, Issue 07, 2016

12. Yeshwant M. Sonkhaskar, Anurag Sahu, Amit Choubey, Amritpal Singh, Raghav Singhal, "Design and development of a plastic bottle crusher" International Journal of Engineering Research \& Technology Vol. 3, Issue 10 (October-2014).

13. T. S. Vasagade, S. S. Tamboli and A. D. Shinde, "Dynamic solid waste collection and management system based on sensors, elevator and GSM," 2017 International Conference on Inventive Communication and Computational Technologies (ICICCT), $\begin{array}{ll}\text { Coimbatore, } & \text { 2017, } \\ \text { 10.1109/ICICCT.2017.7975200. }\end{array}$

14. N. V. Rumyantseva, A. S. Doronin and E. A. Primak, "Improvement of the System of Selective Collection of Household Waste in Latvia," 2018 IEEE International Conference "Management of Municipal Waste as an Important Factor of Sustainable Urban Development" (WASTE), St. Petersburg, 2018, pp. 14-16, doi: 10.1109/WASTE.2018.8554105.

15. Dzobelova, V.B., Berkaeva, A.K., \& Olisaeva, A.V. (2018). Municipal Waste Management in the Republic of North Ossetia-Alanya. 2018 IEEE International Conference"Management of Municipal Waste as an Important Factor of Sustainable Urban Development" (WASTE), 17-18.

16. A. Jain and R. Bagherwal, "Design and implementation of a smart solid waste monitoring and collection system based on Internet of Things," 2017 8th International Conference on Computing, Communication and Networking Technologies (ICCCNT), Delhi, 2017, pp. 1-5, doi: 10.1109/ICCCNT.2017.8204165.

17. Lu, Jia-Wei \& Chang, Ni-Bin \& Zhu, Feng \& Hai, Jing \& Liao, Li. (2018). Smart and green urban solid waste collection system for differentiated collection with integrated sensor networks. 1-5. 10.1109/ICNSC.2018.8361307.

18. Lu, Jia-Wei \& Chang, Ni-Bin \& Liao, Li \& Liao, Meng-Ying. (2015). Smart and Green Urban Solid Waste Collection Systems: Advances, Challenges, and Perspectives. IEEE Systems Journal. PP. 1-14. 10.1109/JSYST.2015.2469544.

19. Dr. Jassim M. Abdulkarim Jaff, 2 Darewan A. Abdulrahman, 3 Zryan O. Ali, 4 Khelan O. Ali, P 5 PMohammed H. Hassan, "Design and Fabrication Recycling of Plastic System", International Journal of Scientific \& Engineering Research, Volume 7, Issue 5, May-2016 1471 ISSN 2229-5518.

20. Y. Huang, B. Baetz, G. Huang, and L. Liu, - Violation analysis for solid waste management systems: an interval fuzzy programming approach, „I Journal of Environmental Management, vol. 65, no. 4, pp. 431 - 446, 2002.

21. G.J. Manderson, $\|$ Composing Agricultural and Industrial Wastes\| in Biotechnology, Institute of Technology and Engineering, Massey University, North New Zealand, 2011.

22. Pankaj M.Patil, Prof. D.B. Sadaphale, student of M.E(Machine Design), Mechanical Engineering Department, SSBT COET, Bambhori-Jalgao, Maharashtra, India 2Faculty Member of Mechanical Engineering Department, SSBT COET, Bambhori-Jalgaon, Maharashtra, India.

23. Ware.E - Control of plastic extruders with multiple temperature zones using a microprocessor based programmable controller system\|, IEEE Transactions on industry applications, VOL 1A-20, N0.4,pp.912-917,1984.

24. Seema Are, Pooja Khatri and Jatin Garg, ॥Proportional Integral Derivative controller Tuning Of Temperature Control system\|, International journal of electronics, Information and systems, Vol.12, No.2,pp.37-42,2010.

25. S. Ravi and P. A. Balakrishnan, \|Stable Self Tuning Fuzzy temperature controller for plastic extruder system\|, International journal of innovative computing information and control,vol.8,no11,pp.7761-7779,2012.

26. A.K. Kochar.\|Dynamic Modelling and control of plastic extrusion processes\|, Automatica,vol.13, N0.2,pp.177-183,1977.

27. C.C. Tasi and C.H. Lu, $\|$ Fuzzy Supervisory predictive PID control of plastic extruder barrel, J. Chinese Institution Engineering, Vol.21,n0.5, pp 619-624,1988.

28. M. P. Groover, Fundamentals of Modern Manufacturing (materials, processes and systems) $4^{\text {th }}$ edition P267-307.

29. Instruction Manual. CBW Granulators. Models 10-12, 10-18 and 10-24 P. 11-36.

\section{AUTHORS PROFILE}

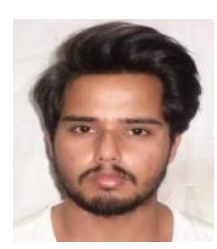

Ashutosh Kr. Singh is doing his final year B.tech. (EN) form GL Bajaj Institute of Technology \& Management Greater Noida, UP, India. His final project is "Design And Fabrication of Smart Waste Collection System."

Published By: Blue Eyes Intelligence Engineering \& Sciences Publication (C) Copyriaht: All riqhts reserved.

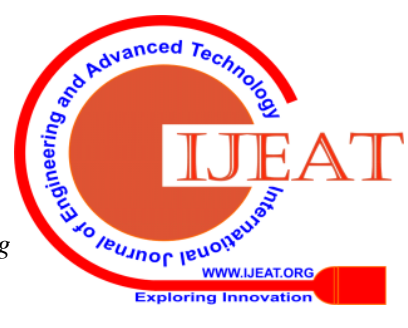




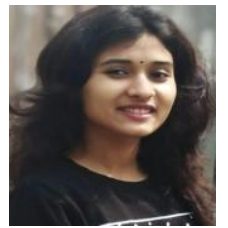

Sonal Singh is doing her final year B.tech. (EN) form GL Bajaj Institute of Technology \& Management Greater Noida, UP, India. Her final project is "Design And Fabrication of Smart Waste Collection System."

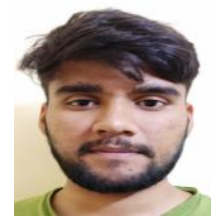

Garvit Saini is doing his final year B.tech. (EN) form GL Bajaj Institute of Technology \& Management Greater Noida, UP, India. His final project is "Design And Fabrication of Smart Waste Collection System."

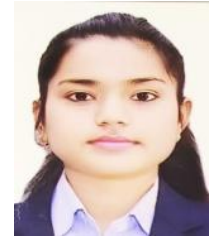

Kushboo is doing her final year B.tech. (EN) form GL Bajaj Institute of Technology \& Management Greater Noida, UP, India. Her final project is "Design And Fabrication of Smart Waste Collection System."

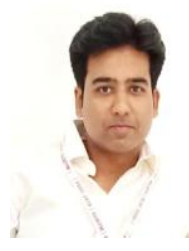

Rajat Mehrotra is an Assistant Professor in the department of Electrical \& Electronics Engineering at GL Bajaj Institute of Technology \& Management, Greater Noida, UP, India. He received his B.Tech. degree in Electrical \& Electronics Engineering from Dr. A.P.J. Abdul Kalam Technical University, Lucknow (Formerly UPTU), in 2008 and M.Tech. degree in Telecommunication Engineering from the same university, in 2014. His research interests are in digital image processing, Biomedical Imaging and Deep Learning. He has published various papers in journals and conferences of national and international repute.

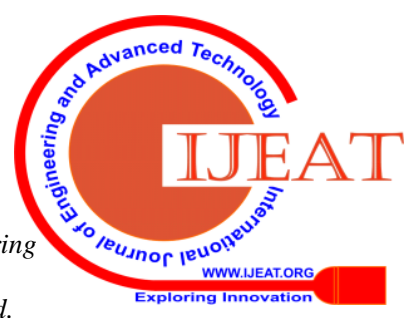

